\title{
Indonesia's Diplomacy in North Natuna Sea in Confronting China to Protect National Interests
}

\author{
Diplomasi Indonesia di Laut Natuna Utara dalam Menghadapi Cina \\ untuk Melindungi Kepentingan Nasional
}

Gerald Theodorus Lumban Toruan

Balitbang Kementerian Pertahanan

Republik Indonesia

theodorus_recht@yahoo.com

\section{Adi Sunaryo}

Balitbang Kementerian Pertahanan

Republik Indonesia

theodorus_recht@yahoo.com

\section{DOI}

https://doi.org/10.37010/fcs.v1i1.270

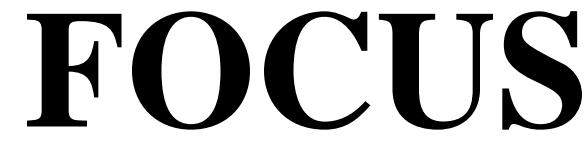

\section{Journal of Social Studies}

\section{Vol. 1 No. 1 \\ FEBRUARI \\ 2020}

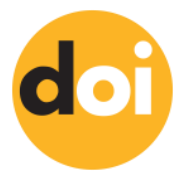

Abstract

North Natuna Sea is become a concern, at the end of 2019 to February 2020 this area was illegally entered by Chinese fishing vessels who wanted to fishing, this vessel was escorted by the Chinese Coast Guard. This escort is in order to

protect their fishing vessels from the pursuit of Indonesian patrol vessels. According to the them that they did not violate Indonesian territory, they said that the North Natuna Sea still belongs to Chinese territory. In the perspective of the international relations what is done by China can disrupt the stability of regional security. This research is a qualitative descriptive with secondary data collection. The formulation of the research question is what kind of diplomacy is

being carried out by Indonesia towards China in the North Natuna Sea. The purpose of this research is to find the right diplomacy concept in dealing with the China in the North Natuna Sea.

Keywords: Indonesia Diplomacy, North Natuna Sea, China, national interest

Abstrak

Laut Natuna Utara menjadi perhatian, pada akhir 2019 hingga Februari 2020 kawasan ini dimasuki secara ilegal oleh kapal ikan China yang hendak memancing, kapal ini dikawal oleh Coast Guard China. Pengawalan ini dalam rangka melindungi kapal nelayan mereka dari kejaran kapal patroli Indonesia.

Menurut mereka bahwa mereka tidak melanggar wilayah Indonesia, mereka mengatakan bahwa Laut Natuna Utara masih milik wilayah Cina. Dalam perspektif hubungan internasional apa yang dilakukan oleh China dapat mengganggu stabilitas keamanan regional. Penelitian ini adalah deskriptif kualitatif dengan pengumpulan data sekunder. Perumusan pertanyaan penelitian adalah diplomasi seperti apa yang sedang dilakukan Indonesia terhadap

Tiongkok di Laut Natuna Utara. Tujuan penelitian ini adalah untuk menemukan konsep diplomasi yang tepat dalam menghadapi China di Laut Natuna Utara.

Kata kunci: Diplomasi Indonesia, Laut Natuna Utara, Cina, kepentingan nasional 


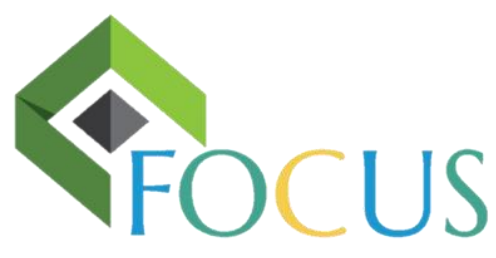

\section{PENDAHULUAN}

Indonesia kembali diuji oleh Cina untuk mempertahankan kedaulatannya di perairan Natuna Utara (Tampi, 2017). Pada bulan Desember 2019 hingga bulan Februari 2020 terjadi pelanggaran wilayah yang dilakukan oleh kapal ikan Cina, tidak hanya itu saja kapal ikan Cina ini juga dikawal oleh kapal Coast Guard mereka untuk menjaga dari adanya tindakan pengusiran dari kapal patroli Indonesia.

Menurut Bakamla Republik Indonesia kapal-kapal Cina mulai terdeteksi masuk ke wilayah perairan Indonesia sekitar tanggal 10 Desember 2019, Direktur Operasional Bakamla mengatakan kapal-kapal tersebut masih berada di landas kontinen Indonesia pada 15 Desember 2019, bahkan kapal-kapal itu mematikan alat radar Automatic Identification System (AIS) (CNN Indonesia, 2020).

Cina mengklaim Perairan Natuna masih wilayah mereka, Pemerintah Indonesia tidak terima dengan klaim tersebut (Muslimah, 2020). Presiden Joko Widodo mengatakan bahwa wilayah Natuna sejak lama masuk teritorial Indonesia. Natuna masuk dalam salah satu dari 514 kabupaten/kota di Indonesia. (Liputan6.com, 2020).

Laut Natuna Utara merupakan laut yang memiliki potensi yang luar biasa dan berada di wilayah Asia Tenggara. Dimana di Laut Natuna Utara banyak terdapat kekayaan alam dan sumber mineral yang bermanfaat bagi Indonesia dan juga bagi negara-negara yang ada di sekitarnya.(Rizal Dwi Novianto et.al, 2020). Potensialnya Laut Natuna Utara memancing negara-negara lain untuk mencoba mengeksplornya, eksplorasi yang dilakukan kebanyakan dengan cara ilegal, salah satunya adalah adanya penangkapan ikan ilegal oleh kapal ikan Cina.

Kapal ikan Cina tidak hanya sekali dua kali melakukan penangkapan ikan ilegal, kejadian ini sudah sering berulang terjadi. Pada tahun 2016 juga pernah kapal ikan Cina KM Kway Fey memasuki perairan Natuna Utara secara ilegal. Tidak hanya Cina yang mengambil ikan secara ilegal di Laut Natuna Utara beberapa negara lain juga pernah seperti Thailand, Vietnam dan Malaysia.

Dalam perspektif hubungan internasional, apa yang dilakukan oleh Cina terhadap klaim di Laut Natuna Utara dapat mengganggu stabilitas keamanan kawasan. Laut Natuna Utara merupakan perbatasan dengan Laut Cina Selatan, hingga saat ini Laut Cina Selatan masih merupakan sengketa dengan negara Filipina, Taiwan, Vietnam, Malaysia. Laut Cina Selatan merupakan jalur pelayaran internasional di mana laut ini menjadi rute kapal-kapal internasional dalam melakukan aktivitas pelayaran dagang secara bebas. (Fitra Deni \& Lukman Sahri, 2017). Meskipun klaim yang dilakukan oleh Cina ini mengganggu stabilitas keamanan kawasan, jalur komunikasi antar negara masih tetap berjalan dengan baik untuk mencarikan solusi yang tepat agar kedua pihak menemukan regulasi yang tepat agar kedepan mendapatkan mekanisme perdamaian bersama (Sudira, 2014)

Pengklaiman ZEE Indonesia di Natuna oleh Cina sebagai wilayah laut teritorial dan penangkapan ikan tradisional mereka dalam peta Sembilan Garis Putus-Putus ini merupakan pelanggaran terhadap UNCLOS 1982. Bahkan Cina mengikutsertakan ZEE Indonesia di Natuna tersebut. [Tribunnews.com, 2015] Alasan Cina mengklaim Laut Cina Selatan, termasuk memasukkan ZEE Indonesia di Natuna, yang berdasarkan masa lampau tidak dapat dibenarkan karena fakta sejarah tidakk dapat dijadikan suatu landasan hukum oleh Cina sebagai penguasa wilayah Laut Cina Selatan. Hal ini bertentangan dengan hukum laut internasional, yakni UNCLOS 1982, di mana Cina merupakan negara yang ikut meratifikasi konvensi tersebut. (Lukman Sahri, 2017).

Penyelesaian masalah Natuna dilakukan secara diplomatis, menurut Kepala Kantor Staf Kepresidenan, pemerintah memiliki cara dan pendekatan sendiri untuk menyelesaikan sengketa Natuna dengan cara soft (lembut) hingga hard (keras).(CNN Indonesia, 2020). 
Indonesia sangat berkepentingan menjaga situasi di wilayah Laut Cina Selatan agar tetap pada situasi yang kondusif, terutama menyangkut ZEE Indonesia di Natuna dikarenakan apabila terjadi konflik atau gesekan di Laut Natuna dengan Cina maka akan mengganggu stabilitas keamanan nasional.

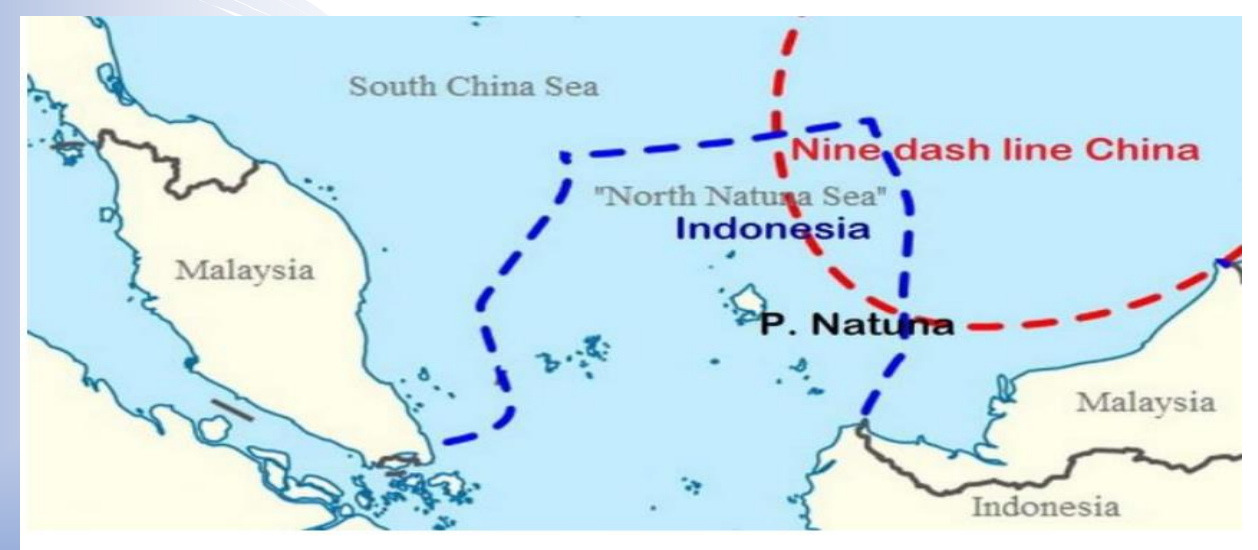

Sumber: maritimindonesia.co.id (2020)

Gambar 1. Profil dan Potensi Laut Natuna Utara

Kabupaten Natuna, adalah salah satu kabupaten di Provinsi Kepulauan Riau, Indonesia. Natuna merupakan kepulauan paling utara di selat Karimata. Di sebelah utara, Natuna berbatasan dengan Vietnam dan Kamboja, di selatan berbatasan dengan Sumatera Selatan dan Jambi, di bagian barat dengan Singapura, Malaysia, Riau dan di bagian timur dengan Malaysia Timur dan Kalimantan Barat. (Disparbud.natunakab.go.id, 2020)

Natuna berađa pada jalur pelayaran internasional Hongkong, Jepang, Korea dan Taiwan. Kabupaten ini terkenal dengan penghasil minyak dan gas. Cadangan minyak bumi Natuna diperkirakan mencapai 14.386.470 barel, sedangkan gas bumi 112.356.680 barel.Sejarah Kabupaten Natuna tidak dapat dipisahkan dari sejarah Kabupaten Kepulauan Riau, karena sebelum berdiri sendiri sebagai daerah otonomi, Kabupaten Natuna merupakan bahagian dan Wilayah Kepulauan Riau. Kabupaten Natuna dibentuk berdasarkan Undang-Undang No. 53 Tahun 1999 yang disahkan pada tanggal 12 Oktober 1999, dengan dilantiknya Bupati Natuna Drs. H. Andi Rivai Siregar oleh Menteri Dalam Negeri ad interm Jenderal TNI Faisal Tanjung di Jakarta.

Laut Natuna yang masuk ke dalam Zona Ekonomi Eksklusif (ZEE) Indonesia diklaim oleh pemerintah Cina sebagai kawasan perikanan tradisionalnya, ini menyebabkan banyak nelayan-nelayan Cina yang secara bebas menangkap ikan di kawasan tersebut yang kemudian merugikan pihak negara Indonesia.

Laut Natuna Utara merupakan laut yang potensial, berdasarkan data Kementerian Kelautan dan Perikanan Perairan Natuna memiliki potensi ikan pelagis mencapai 327.976 ton, ikan demersal 159.700 ton, cumi-cumi 23.499 ton, rajungan 9.711 ton, kepiting 2.318 ton, dan lobster 1.421 ton per tahun. Kemudian, juga ada potensi ikan kerapu, tongkol, teri, tenggiri, ekor kuning, udang putih, dan lainnya. (CNN Indonesia, 7 Januari 2020)

Selain menyimpan potensi perikanan yang menjanjikan, Laut Natuna juga memiliki potensi migas yang cukup kaya.Berdasarkan data dari Satuan Kerja Khusus Pelaksana Kegiatan Usaha Hulu Migas (SKK Migas) total produksi minyak dari blok-blok yang berada di Natuna adalah 25.447 barel per hari, selain itu cadangan minyaknya diperkirakan mencapai 36 juta barel, tidak hanya minyak Natuna juga memproduksi gas bumi sebesar 489,21 MMSCFD. (SKK Migas, 2020) 


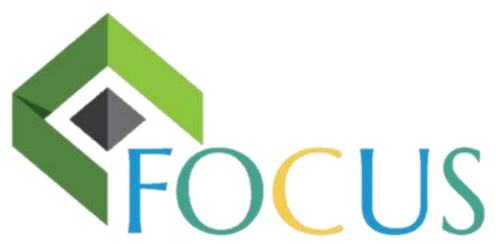

Dari kekayaan sumber daya alam yang dimiliki oleh Natuna, sudah seharusnyalah Indonesia melindungi kekayaan ini dari negara asing. Sektor perikanan yang paling sering mengalami kerugian akibat adanya praktikpraktik illegal fishing oleh kapal-kapal ikan asing terutama kapal ikan Cina.

Konsep kepentingan nasional diperlukan dan penting untuk menjelaskan bagaimana perilaku negara dalam sistem internasional. Dalam hal ini, kepentingan nasional menjadi key concept untuk perumusan kebijakan luar negeri. Kepentingan nasional dapat dijelaskan sebagai tujuan fundamental dan faktor penentu akhir yang mengarahkan para pembuat keputusan dari suatu negara dalam membuat atau merumuskan kebijakan luar negerinya. Kepentingan nasional dari suatu negara secara khas merupakan unsur-unsur yang membentuk kebutuhan negara yang paling vital, seperti pertahanan, keamanan, militer dan kesejahteraan ekonomi. (Yani, 2017)

Konsep kepentingan nasional menurut Hans J. Morgenthau dibagi menjadi tiga bagian utama, adalah sebagai berikut (Morgenthau, 1948):

1. Perlindungan terhadap identitas fisik, dalam arti mampu mempertahankan integritas teritorialnya;

2. Perlindungan terhadap identitas politik, dalam arti mampu mempertahankan rezim ekonomi dan politiknya;

3. Perlindungan terhadap kulturnya, dalam artian mampu mempertahankan linguistik dan sejarahnya.

Mengutip pernyataan dari AM. Hendropriyono mengatakan bahwa dalam konteks perselisihan Indonesia dengan Cina di Laut Natuna harus bisa menjawab dua tantangan; pertama, penegakan hukum dengan risiko pertempuran laut; kedua, mengamankan kepentingan nasional Indonesia dengan menghindarkan risiko perang. (Detiknews, 2020)

Kepentingan nasional tercipta dari kebutuhan suatu negara. Kepentingan ini dapat dilihat dari kondisi internalnya,baik dari kondisi politik-ekonomi,militer,dan sosial-budaya. Kepentingan juga didasari akan suatu 'power' yang ingin diciptakan sehingga negara dapat memberikan dampak langsung bagi pertimbangan negara agar dapat pengakuan dunia. Peran suatu negara dalam memberikan bahan sebagai dasar dari kepentingan nasional tidak dipungkiri akan menjadi kacamata masyarakat internasional sebagai negara yang menjalin hubungan yang terlampir dari kebijakan luar negerinya. (Puslitbang Strahan Balitbang Kemhan, 2019)

Menurut the Chamber's Twentieth Century Dictionary (1976) diplomasi adalah "the art of negotiation, especially of treaties between states; political skill" dalam bahasa Indonesianya (seni berunding, khususnya tentang perjanjian di antara negara-negara; keahlian politik). Di sini, yang pertama menekankan kegiatannya sedangkan yang kedua meletakkan penekanan pada senin berundingnya.

Sir Earnest Satow (1961) dalam bukunya Guide to Diplomatic Practice memberikan karakterisasi diplomasi yang bagus meskipun tidak jelas dan kurang akurat. Ia mengatakan diplomasi adalah "the application of intelligence and tact to conduct of official relations between the government of independent states" (penerapan kepandaian dan taktik pada pelaksanaan hubungan resmi antara pemerintah negara-negara berdaulat).

K.M. Panikkar (1957) dalam bukunya The Principle and Practice of Diplomacy menyatakan, bahwa diplomasi dalam hubungannya dengan politik internasional, adalah seni mengedepankan kepentingan suatu negara dalam hubungannya dengan negara lain. Ivo D. Duchacek (1961) berpendapat, "Diplomasi biasanya didefinisikan sebagai praktik pelaksanaan politik luar negeri suatu negara dengan cara negosiasi dengan negara lain.

Dalam mengkaji definisi-definisi yang telah disebut di atas beberapa hal tampak jelas; pertama, jelas bahwa unsur-unsur pokok diplomasi adalah negosiasi; kedua, negosiasi dilakukan untuk mengedepankan kepentingan negara; ketiga, tindakan-tindakan diplomatik diambil untuk menjaga dan memajukan kepentingan 
nasional sejauh mungkin bisa dilaksanakan dengan sarana damai. Oleh karena itu pemeliharaan perdamaian tanpa merusak kepentingan nasional adalah tujuan utama diplomasi. (S.L. Roy, 1991).

Kautilya, seorang diplomat kawakan India kuno, dalam bukunya Arthasastra menekankan empat tujuan htama diplomasi, yaitu acquisition (perolehan), preservation (pemeliharaan), augmentation (penambahan), dan proper distribution (pembagian yang adil) (R.P. Kangle, 1972). Ciri-ciri diplomasi Indonesia sebagaimana penjelasan Pasal 4 Undang-undang Negara Republik Indonesia nomor 37 tahun 1999 tentang Hubungan Luar Negeri, adalah: pertama, diplomasi yang menggambarkan jati diri diplomasi Indonesia; kedua, diplomasi yang tidak sekedar bersifat rutin, dapat menempuh cara-cara non konvensional, cara-cara yang tidak terlalu terikat pada kelaziman protokoler ataupun tugas rutin belaka, tanpa mengabaikan norma-norma dasar dalam tata krama diplomasi internasional; ketiga, diplomasi yang dibekali keteguhan dalam prinsip dan pendirian, ketegasan dalam sikap, kegigihan dalam upaya namun luwes dan rasional dalam pendekatan, yang bersumber pada kepercayaan diri sendiri; keempat, diplomasi yang mencari keharmonisan, keadilan dan keserasian dalam hubungan antar negara, menjauhi sikap konfrontasi ataupun politik kekerasan atau kekuasaan (power politics), menyumbang penyelesaian berbagai konflik dan permasalahan di dunia, dengan memperbanyak kawan dan mengurangi lawan ; kelima, diplomasi yang ditopang oleh profesionalisme yang tangguh dan tanggap, tidak sekedar bersikap reaktif tetapi mampu secara aktif, kreatif, dan antisipatif berperan dan berprakarsa.

Berdasarkan penjelasan latar belakang di atas maka rumusan masalah penelitian ini adalah Diplomasi seperti apakah yang dilakukan oleh Indonesia terhadap Cina di Laut Natuna Utara. Tujuan dari penelitian ini adalah terciptanya suatu kebijakan diplomasi untuk menghadapi agresivitas Cina agar tidak berulang kali melakukan pelanggaran yang sama di Laut Natuna Utara.

\section{METOPE}

Metode penelitian yang dgunakan dalam penelitian ini adalah metode penelitian kualitatif. Analisis penelitian menggunakan analisis kritikal terhadap topik tertentu yang disebut dengan literatur review (Bungin, 2020). Adapun sumber literatur review penelitian ini adalah berasal dari publikasi jurnal bereputasi, berita online,website, majalah dan buku ilmiah lainnya.

\section{HASIL DAN PEMBAHASAN}

Menggunakan diplomasi pertahanan adalah salah satu cara Indonesia melalui diplomasi untuk menghadapi agresivitas Cina, di mana tujuan dari diplomasi pertahanan (secara teoritis), antara lain sebagai kehadiran atau perwakilan (representation); mempunyai efek atau daya tangkal (detterent effect) dengan memberikan penerangan tentang apa yang kita kerjakan (transforming the way we work); melakukan negosiasi dan posisi tawar (negotiation and bargaining position); meningkatkan kemampuan (increasing capability); meningkatkan kredibilitas (increasing credibility); menurunkan keinginan negara yang berseberangan kepentingan untuk melakukan hal-hall yang tidak diinginkan (decreasing opponent's stakes); pengumpulan data intelijen atau informasi dan laporan (information gathering or intelligence); membentuk opini publik (to form public opinion); mempromosikan hukum internasional (to promote international law); membangun saling percaya (confidence building measures) atau trust building; dan pengembangan wilayah. (Simamora, 2013).

Diplomasi pertahanan dilakukan pada masa damai menggunakan kekuatan bersenjata dan infrastruktur terkait sebagai alat kebijakan keamanan dan kebijakan luar negeri. Diplomasi pertahanan juga merupakan 


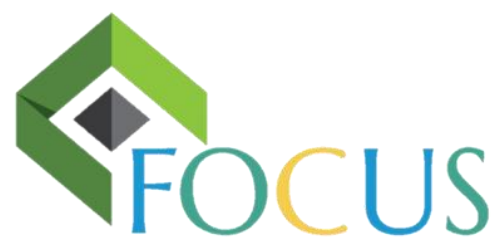

\section{oreñ Ancecess}

sebuah proses yang tidak hanya melibatkan aktor negara saja (seperti politisi, kekuatan bersenjata atau badan intelijen), namun juga organisasi non-pemerintah, think tank dan masyarakat sipil.

Diplomasi pertahanan dalam rangka untuk menghadapi Cina adalah dengan mengadakan kegiatankegiatan pertahanan seperti pertukaran personel, kunjungan pesawat atau kapal perang, kunjungan pejabat tinggi negara, pertemuan bilateral, pendidikan dan pelatihan anggota militer, serta hubungan bilateral dan forum-forum multilateral salah satunya adalah dengan ASEAN Regional Forum. Dalam prakteknya ada empat jenis tindakan praktek diplomasi pertahanan maritim, antara lain communication, constrains, transparency, dan verification (Adikara \& Munandar, 2021).

Seperti yang disebutkan dalam Pembukaan Undang-Undang Dasar Negara Republik Indonesia tahun 1945, negara Indonesia menjunjung tinggi kemerdekaan dan kedaulatan setiap negara. Indonesia bukanlah negara agresor, setiap perselisihan, konflik ataupun sengketa yang timbul dengan negara lain ataupun negara tetangga, Indonesia mengedepankan upaya diplomatik.

Dalam rangka menjaga kedaulatan negara, keutuhan dan keselamatan banga, Indonesia tidak akan membiarkan negara lain menyerang, mengancam, menduduki atau menghancurkan negara Indonesia. Dalam menghadapi ancaman militer dari Cina di Laut Natuna Utara, Indonesia mengembangkan strategi pertahanan defensif aktif. Salah satu wujudnya adalah dengan mengedepankan diplomasi sebagai garis terdepan pertahanan negara (first line defence). Dalam kaitannya dengan kasus di Laut Natuna Utara, perang dapat dicegah dengan melakukan pendekatan politik melalui upaya diplomasi. Upaya diplomasi ini berintikan peran pertahanan nirmiliter melalui politik dan ekonomoi, berjalan dengan itu pertahanan militer dan nirmiliter lainnya disiapsiagakan untuk memperkut upaya diplomasi (diplomacy backed by force) sekaligus untuk melakukan tahapan lanjutan dalam rangka apabila terjadinya deathlock diplomasi antar negara yang berselisih.

\section{PENUTUP}

Berdasarkan dari hasil dan pembahasan yang telah disampaikan di atas, maka kesimpulan yang dapat diberikan oleh penulis adalah diplomasi yang dilakukan oleh pemerintah era Presiden Joko Widodo untuk menghadapi Cina di Laut Natuna Utara adalah dengan model diplomasi pertahanan. Diplomasi pertahanan yang dilakukan adalah dengan mengerahkan seluruh kapal patroli Indonesia ke Laut Natuna Utara. Diplomasi pertahanan dilakukan dalam rangka untuk mencegah terjadinya konflik terbuka di Laut Natuna Utara.

Menghadapi Cina tidak bisa dengan cara frontal harus dengan pendekatan yang halus, seperti yang telah dilakukan oleh Presiden Joko Widodo pada 2016 dengan menggelar rapat di kapal perang Indonesia kemudian pada 2020 dengan memberikan sertifikat tanah kepada penduduk Natuna. Kementerian yang berwenang melakukan diplomasi pertahanan adalah Kementerian Pertahanan.

\section{DAFTAR PUSTAKA}

Adikara, A. P. B., \& Munandar, A. I. (2021). Tantangan Kebijakan Diplomasi Pertahanan Maritim Indonesia Dalam Penyelesaian Konflik Laut Natuna Utara. Jurnal Studi Diplomasi Dan Keamanan, 13(1).

Bungin, B. (2020). Post-Qualitative: Social Research Methods. Jakarta: Kencana.

CNN Indonesia, 7 Januari 2020

Disparbud.natunakab.go.id, 2020

Duchacek Ivo. D. (1961). Conflict and Cooperation Among Nations. New York 
Deni. F., \& Sahri, L. (2017). Upaya Diplomasi Indonesia Terhadap Klaim China Atas Zona Ekonomi Eklusif Indonesia Di Laut Natuna. Jurnal International and Diplomacy. Vol.3, No. 1. Universitas Satya Negara Indonesia.

Kangle R.P. (1972). The Kautilya Arthasastra Part II. Bombay.

Litbang (2019). Konsep Diplomasi Pertahanan Dalam Mengantisipasi Perkembangan Politik Dunia Lima Tahun Ke Depan”. Puslitbang Strahan Balitbang Kemhan Republik Indonesia. Jakarta.

Morgenthau, Hans J, Politics Among Nations. Cal

Muslimah, F., \& Adi, D. P. (2020). Analisis Konflik Kepulauan Natuna Pasa Tahun 2016-2019. Jurnal AlAhkam: Jurnal Hukum Pidana Islam, 2(2), 10-19.

Dwi. N.R., et.al. (2020) . Penyelesaian Sengketa Di Laut Natuna Utara. Jurnal Hukum Bisnis Bonum Commune Volume 3 Nomor 1 Februari 2020. Surabaya: Universitas 17 Agustus 1945.

Panikkar K.M. (1957) The Principle and Practice of Diplomacy. Bombay

Roy S.L. (1991). Diplomasi. Jakarta: Rajawali Pers.

Satow E.A. (1957). A Guide to Diplomatic Practice. London

Simamora P. (2013). Peluang dan Tantangan Diplomasi Pertahanan. Yogyakarta: Graha Ilmu.

Sudira, I. N. (2014). Konflik Laut Cina Selatan dan Politik Luar Negeri Indonesia ke Amerika dan Eropa. Jurnal Ilmiah Hubungan Internasional, 10(2).

Tampi, B. (2018). Konflik Kepulauan Natuna Antara Indonesia dengan China (Suatu Kajian Yuridis). Jurnal Hukum Unsrat, 23(10).

The Chamber's Twentieth Century Dictionary, 1976

Yani M.Yanyan,et.al. (2017). Pengantar Studi Keamanan. Malang: Intrans Publishing. 